\title{
Kegiatan Donor Darah Sebagai Gerakan Sosial di Jurusan Teknik Kimia ITATS
}

\section{Blood Donation Activities as a Social Movement in ITATS Chemical Engineering Department}

\author{
${ }^{1 *}$ Erlinda Ningsih, ${ }^{2)}$ Kartika Udyani, ${ }^{3)}$ Dian Yanuartita Purwaningsih, ${ }^{4)}$ Axo Syamboga, \\ ${ }^{5)}$ M. Arjun Santosa, ${ }^{6}$ Dwi Setiawan \\ 1,2,3,4,5,6) Program Studi Teknik Kimia, Fakultas Teknologi Industri \\ Institut Teknologi Adhi Tama Surabaya \\ J1. Arief Rahman Hakim no. 100 Surabaya \\ *email: erlindaningsih84@itats.ac.id
}

DOI:

10.30595/jppm.v5i1.8592

\section{Histori Artikel:}

Diajukan:

$17 / 09 / 2020$

Diterima:

$10 / 01 / 2022$

Diterbitkan:

$17 / 02 / 2022$

\section{ABSTRAK}

Donor darah merupakan sebuah kegiatan dimana seseorang secara sukarela memberikan darahnya yang nantinya akan disimpan di Bank Darah untuk keperluan transfusi bagi yang memerlukan. Umumnya kebutuhan darah tidak sebanding dengan jumlah pendonor. Informasi pentingnya donor danar masih banyak yang belum mengetahui. Kegiatan ini bertujuan untuk membantu Palang Merah Indonesia Kota Surabaya memenuhi dan meningkatkan stok darah yang dibutuhkan di Kota Surabaya dan mengsosialisasikan kepada seluruh mahasiswa Institut Teknologi Adhi Tama Surabaya bahwa pentingnya donor darah. Kegiatan donor darah ini bekerja sama antara Himpunan Mahasiswa Teknik Kimia dan Palang Merah Indonesia Donor Kota Surabaya. Teknis pelaksanaan kegiatan ini terbagi menjadi 4 tahap yaitu penyebaran formulir pendonor, Pendaftaran pendonor, Pengecekan kesehatan, donor darah. Kegiatan donor darah ini tidak hanya diikuti oleh civitas jurusan teknik kimia tetapi juga civitas fakultas yaitu mahasiswa Teknik dan dosen. Pelaksanaan kegiatan donor darah ini berlangsung 1 hari dengan peserta donor darah 60 orang dan berjalan dengan lancar. Partisipasi yang terlibat terdiri dari 52 mahasiswa dan 8 dosen. Berdasarkan pengecekan kesehatan didapatkan 40 peserta tidak memenuhi syarat untuk menjadi penderma darah dan 20 orang memenuhi, sehingga mendapatkan 20 kantong darah.

Kata kunci: Donor Darah; Gerakan Sosial; Teknik Kimia

\begin{abstract}
Blood donation is an activity where a person voluntarily gives blood which will later be stored in a blood bank for transfusion purposes for those in need. Generally, blood requirements are not proportional to the number of donors. Information on the importance of the danar donors is still unknown. This activity aims to help the Surabaya City Indonesian Red Cross meet and increase the blood stock needed in the city of Surabaya and to socialize all students of the Surabaya Adhi Tama Institute of Technology about the importance of blood donation. This blood donation activity is a collaboration between the Chemical Engineering Student Association and the Indonesian Red Cross Donor City of Surabaya. The technical implementation of this activity is divided into 4 stages, namely distribution of donor forms, donor registration, health checks, blood donors. This blood donation activity was not only attended by the chemical engineering community but also the faculty members, namely engineering students and lecturers. The blood donation activity lasted for 1 day with 60 blood donor participants and it went well. The participants involved consisted of 52 students and 8 lecturers. Based on the health check, it was found that 40 participants did not meet the requirements to become blood donors and 20 people did, so they received 20 bags of blood.
\end{abstract}


Keywords: Blood Donation; Social Movements; Chemical Engineering

\section{PENDAHULUAN}

Donor darah merupakan kegiatan untuk menyumbangkan darah yang dilakukan oleh penderma darah secara sukarela untuk menolong orang yang membutuhkan dan hasil darah yang didapatkan disimpan di Bank Darah (Aigner et al., 2003). Donor darah yang rutin dilakukan secara rutin tiga bulan sekali, akan memicu untuk memproduksi sel-sel darah baru, di mana sel darah baru ini berfungsi untuk oksigenasi dan menggangkut sari-sari makanan(Widarto, 2011). Dampak positif dan negatif akibat donor darah ini perlu diketahui oleh penderma darah(Saputra et al., 2014). Salah satu manfaat orang yang telah melakukan donor darah adalah dapat mengurangi resiko penyakit jantung (Pule et al., 2014). Pelaksanaan donor darah dilakukan di Perusahaan, di kampus, di Instansi, dapat mempermudah para penderma darah untuk melakukan donor darah tanpa harus ke PMI atau pusat donor darah (Harsiwi \& Arsini, 2018).

Persediaan darah di Bank Darah sangat penting bagi masyarakat yang sedang membutuhkan, khususnya di Rumah Sakit. Berdasarkan data PMI pada tahun 2013, Palang Merah Indonesia (PMI) hanya mampu mengumpulkan 2.480.352 kantong darah. Sedangkan idealnya PMI harus memiliki kantong darah sebanyak 2,5\% dari jumlah penduduk yang berjumlah 247.837.073 jiwa yaitu 4.956.741 kantong darah (Kementerian Kesehatan RI, 2014). Data ini menunjukkan bahwa pasokan darah Indonesia belum ideal atau masih kurang (Hapsari \& Herdiana, 2012).

Untuk mengatasi keterbatasan pasokan darah, perlu diketahui faktor-faktor yang berpengaruh. Faktor yang berpengaruh berdasarkan hasil penelitian disimpulkan bahwa pengetahuan, sikap dan motivasi terhadap donor darah (Baig et al., 2013; Olaiya et al., 2004; Wardati et al., 2019) Untuk meningkatkan minat orang agar mendermakan darahnya, perlu dilakukan sosialisasi dan motivasi. Pemberian informasi dan edukasi yang bertujuan untuk merubah pemahaman dan perilaku masyarakat untuk donor darah sudah dilakukan oleh Palang Merah Indonesia dengan menyebarkan brosur dan ceramah kepada penderma darah pertama(Kementerian Kesehatan RI, 2014).

Surabaya merupakan kota besar dan memiliki tingkat kesadaran masyarakatnya untuk mendermakan darahnya tertinggi kedua setelah DKI Jakarta (Hapsari \& Herdiana, 2012). Namun fakta di lapangan PMI Surabaya sering mengalami kekurangan stok darah(Trade, n.d.). Hal ini disebabkan oleh permintaan darah yang tinggi dan PMI Surabaya juga turut melayani permintaan kebutuhan darah daerah luar Surabaya dan Jawa Timur sekitarnya.

Berdasarkan uraian di atas, maka kegiatan donor darah ini diselenggarakan bertujuan untuk membantu menambah pasokan darah di PMI Surabaya. Kegiatan ini bersifat rutin dalam 1 tahun sekali diadakan kerja sama dengan PMI Surabaya. Harapan dari kegiatan ini, selain meningkatkan pasokan darah juga mengubah perilaku masyarakat khususnya mahasiswa Teknik Kimia ITATS dan sekitarnya untuk mendermakan darah.

\section{METODE}

Kegiatan gerakan social donor darah ini merupakan salah satu rangkaian kegiatan Himpunan Mahasiswa Teknik Kimia dalam event Chemical Festival 2019. Kegiatan donor darah ini bekerja sama dengan PMI Surabaya. Waktu pelaksanaan kegiatan ini berdasarkan kesepakatan dan jadwal kosong pihak PMI Surabaya.

\section{Waktu dan Tempat}

Kegiatan donor darah dilakukan pada tanggal 27 November 2019 pukul 13.00 sampai dengan 16.00 di Ruang Sidang Teknik Kimia Institut Teknologi Adhi Tama Surabaya.

\section{Pelaksanaan Kegiatan}

Pelaksanaan kegiatan ini meliputi penyebaran formulir pendonor, pendaftaran pendonor, Pengecekan kesehatan, Pelaksanaan donor 
darah. Kegiatan ini melibatkan mahasiswa Teknik Kimia yang aktif di Himpunan Mahasiswa Teknik Kimia, PMI Surabaya, Civitas akademis di lingkungan Fakultas Teknologi Industri. Untuk 3 tahap kegiatan pelaksananya adalah team dari PMI.

\section{HASIL DAN PEMBAHASAN}

Himpunan Mahasiswa Teknik Kimia setiap tahun memiliki agenda rutin yaitu Chemical Festival. Dalam event tersebut memiliki beberapa acara diantaranya perlombaan, bakti sosial, dan bazar. Untuk tahun ini, kegiatan bakti sosial diadakan dalam bentuk donor darah bekerja sama dengan PMI Surabaya. Kegiatan donor darah ini dilaksanakan melalui 4 tahap yaitu penyebaran formulir pendonr, pendaftaran pendonor, Pengecekan kesehatan, Pelaksanaan donor darah.

\section{Penyebaran Formulir Pendonor}

Kesepakatan waktu pelaksanaan antara panitia dan PMI Surabaya. Setelah ada kesepakatan, pihak panitia 2 pekan sebelum pelaksanaan menyebarkan formulir pendonor kepada civitas akademik di lingkungan Teknik Kimia dan Fakultas Teknologi Industri ITATS. Sebanyak 150 lembar formulir disebar baik kepada mahasiswa, karyawan, dan dosen. Informasi awal untuk menarik peminat dipasang brosur di setiap papan pengumuman semua jurusan yang ada di kampus ITATS yang bertujuan tentang informasi ajakan untuk donor darah dan waktu pelaksanaan. Adanya informasi awal ini diharapkan dapat meningkatkan minat dan respon yang baik para civitas kampus untuk mendonorkan darah, hal ini sesuai dengan penelitian yang dilakukan oleh (Sugesty et al., 2019). Peningkatan minat mencapai $75 \%$ dengan adanya informasi awal kepada pendonor baik pendonor yang sudah pernah dan pendonor pemula (Sugesty et al., 2019). Sebanyak 150 lembar formulir yang sudah tersebar, ada 60 formulir yang kembali ke panitia sebagai bentuk partisipan untuk menjadi pendonor.

Pelaksanaan donor darah di kampus merupakan tempat yang strategis, karena kemungkinan besar banyak yang akan menjadi penderma darah. Namun fakta di lapangan banyak alasan yang sebagai bentuk penolakan diantaranya takut melihat darah, takut jarum, takut merasa sakit, takut menjadi anemia, takut lemas, dan takut terinfeksi. Selain itu, banyak diantara mereka kurangnya info tentang manfaat donor darah. Pengetahuan ini sangat penting, karena akan berdampak terhadap perilaku masyarakat dan kesadarannya untuk mendorong mereka mendonorkan darahnya (Wardati et al., 2019).

\section{Pendaftaran Pendonor}

Pada hari pelaksanaan donor darah, peserta yang mengisi formulir pendonor dating dan dilakukan pendataan oleh petugas PMI. Pendataan ini akan masuk dalam data base berbasis komputerisasi PMI terlihat pada Gambar 1, bertujuan untuk mempermudah dan mempercepat proses donor darah(Sonita \& Kundari, 2019). Data penderma darah yang lengkap dapat mempermudah pihak PMI untuk mengingatkan pendonor untuk donor lagi. Selain pendataan, para pendonor diberikan arahan dan pengetahuan tentang donor darah, manfaatnya, dan efek sampingnya. Hal ini bertujuan agar penderma merasa aman dan tenang khususnya pendonor pemula.

\section{Pengecekan Kesehatan}

Langkah berikutnya bagi pendonor darah adalah dilakukan seleksi awal yang terlihat pada Gambar 2 diantaranya timbang berat badan, tekanan darah dan anamnesa(Rahayu \& Usdyapriasti, 2018) kepada semua peserta penderma darah. 


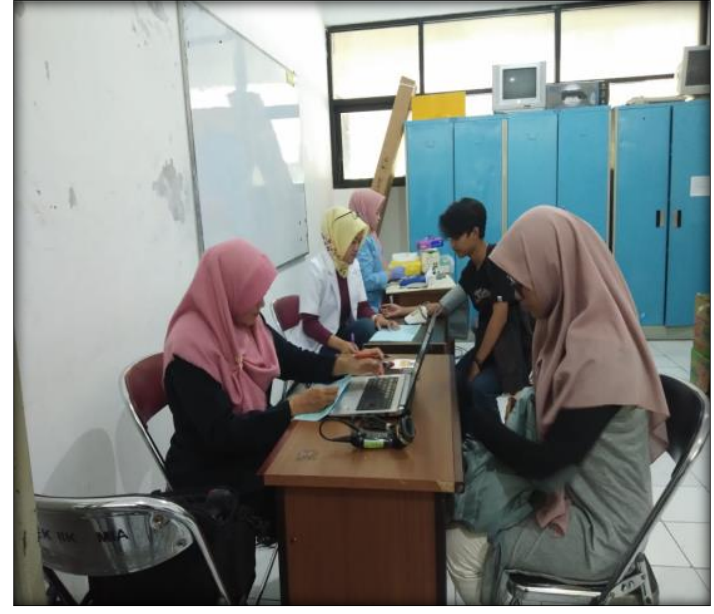

Gambar 1. Pendataan Peserta Donor Darah

Penderma darah harus memenuhi prasyarat sebelum mendonorkan darahnya diantaranya memiliki berat badan minimal $45 \mathrm{~kg}$, tekanan darah minimal 110/70 $\mathrm{mmhg}$, dan istirahat kurang lebih 6 jam (Sonita \& Kundari, 2019). Umumnya peserta yang mengisi formulir adalah mahasiswa memenuhi berat badan minimal dan tidak memiliki tekanan darah rendah.

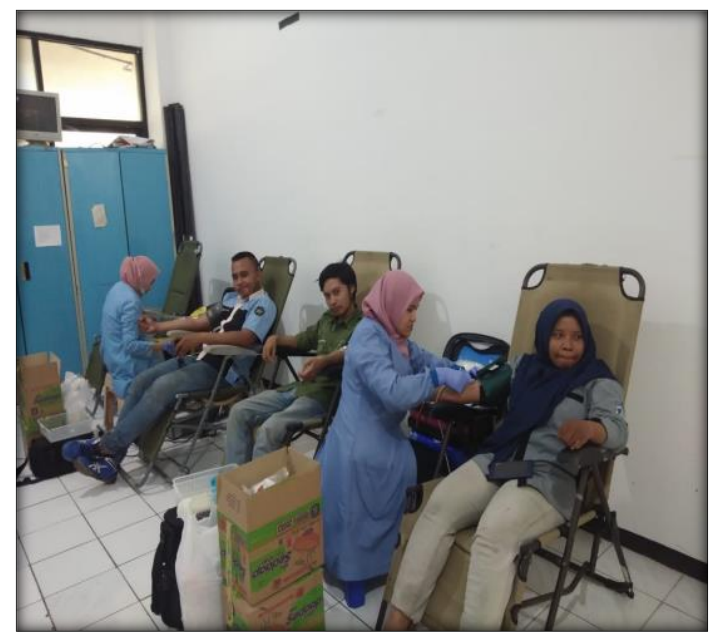

Gambar 2. Tes Kesehatan Peserta Donor Darah

Berdasarkan hasil pendataan peserta, 40 peserta dinyatakan tidak memenuhi syarat kesehatan sehingga tidak bisa mendonorkan darahnya. Faktor yang paling banyak adalah tekanan darah yang rendah, karena malam harinya mereka bergadang. Peserta yang sebagian besar mahasiswa begadang karena mengerjakan tugas, nongkrong, dan memiliki pola hidup yang tidak sehat seperti perokok. Beberapa hal yang penting dilakukan oleh pendonor baik sebelum dan sesudah :

a. Meminum banyak cairan dan makan makanan yang rendah lemak dan mengandung tinggi zat besi sebelum mendonor.

b. Setelah donor, pendonor segera mengkonsumsi makanan yang meningkatkan kadar gula dan Vitamin C.

c. Pendonor dianjurkan untuk tidak mengkonsumsi makanan yang dapat menggangu absorbsi zat besi selama beberapa hari setelah donor, seperti teh, soda atau kopi(Rahayu \& Usdyapriasti, 2018). Umumnya para peserta yang sebagian peserta adalah mahasiswa masih kurang informasi tentang hal-hal yang perlu diperhatikan dan dilakukan sebelum donor darah.

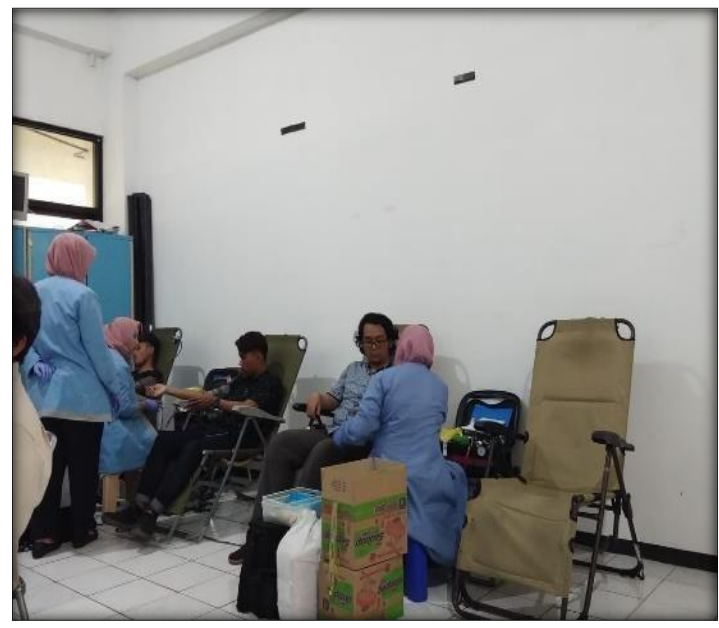

Gambar 3. Pengambilan Darah Peserta Donor Darah

\section{Pelaksanaan donor darah}

Peserta penderma darah yang lolos tes kesehatan dilanjutkan duduk di kursi yang disediakan untuk pengambilan darahnya. Pelaksanaan pengambilan darah berdasarkan urutan peserta yang datang dan yang lolos tes kesehatan, hal ini terlihat pada Gambar 3. Peserta yang lolos atau memenuhi syarat adalah 20 orang, sehingga pihak PMI hanya mendapatkan 20 kantong. Berdasarkan data base yang dimiliki pihak PMI dan wawancara yang dilakukan, peserta yang dinyatakan lolos adalah mereka yang penderma darah rutin atau pernah donor. Sedangkan yang tidak lolos 
umumnya mereka pendonor pemula yang kurang mendapatkan informasi tentang seputar donor darah.

\section{SIMPULAN}

Kegiatan donor darah yang diselenggarakan Himpunan Mahasiswa Teknik Kimia ITATS bekerja sama dengan PMI Surabaya berjalan dengan baik dan lancar. Pada kegiatan ini, diikuti oleh 60 peserta penderma darah. Berdasarkan hasil tes kesehatan dan wawancara dari peserta 60 yang mendaftar hanya 20 orang yang memenuhi syarat sebagai penderma darah. Sehingga PMI mendapatkan 20 kantong.

\section{DAFTAR PUSTAKA}

Aigner, C., Seebacher, G., \& Klepetko, W. (2003). Donor selection. Chest Surgery Clinics of North America, 13(3), 429-442. https://doi.org/10.1016/S10523359(03)00051-6

Baig, M., Habib, H., Haji, A. H., Alsharief, F. T., Noor, A. M., \& Makki, R. G. (2013). Knowledge, misconceptions and motivations towards blood donation among university students in Saudi Arabia. Pakistan Journal of Medical Sciences, 29(6), 1295-1299. https://doi.org/10.12669/pjms.296.4137

Hapsari, N. Y. H., \& Herdiana, I. (2012). Hubungan antara Self-Esteem dengan Intensi Perilaku Prososial Donor Darah pada Donor di Unit Donor Darah PMI Surabaya. Jurnal Psikologi Kepribadian Dan Sosial, 1(3), 175-176. http://journal.unair.ac.id/filerPDF/Jurnal 110710223_Nur Yuli.pdf

Harsiwi, U. B., \& Arsini, L. D. D. (2018). TINJAUAN KEGIATAN DONOR DARAH TERHADAP KESEHATAN Udi Budi Harsiwi , 2 Liss Dyah Dewi Arini APIKES Citra Medika Surakarta. 8(1).

Kementerian Kesehatan RI. (2014). InfodatinDonor-Darah.Pdf (pp. 1-7).

Olaiya, M., Alakija, W., Ajala, A., \& Olatunji, R. (2004). Knowledge, attitudes, beliefs and motivations towards blood.
Transfusion Medicine, 14(1), 13-17. https://doi.org/10.1111/j.0958-

7578.2004.00474.x

Pule, P. I., Rachaba, B., Magafu, M. G. M. D., \& Habte, D. (2014). Factors Associated with Intention to Donate Blood: Sociodemographic and Past Experience Variables. Journal of Blood Transfusion, 2014, $1-7$. https://doi.org/10.1155/2014/571678

Rahayu, S., \& Usdyapriasti, S. (2018). Pelaksanaan Donor Darah Di Kelurahan Kedungsuren Kecamatan Kaliwungu Selatan Kabupaten Kendal. Abdimas Unwahas, 3(1), 33-35. https://doi.org/10.31942/abd.v3i1.2236

Saputra, M. A., Informasi, J. S., \& Informasi, F. T. (2014). Pengelolaan Donor Darah. $3(2)$.

Sonita, A., \& Kundari, R. (2019). Aplikasi Seleksi Calon Pendonor Darah Menggunakan Algoritme C4.5. Pseudocode, 6(2), 96-103. https://doi.org/10.33369/pseudocode.6.2. 96-103

Sugesty, Y., Sulastri, \& Proborini, R. (2019). Pengaruh Pemberian Informasi melalui Brosur dan Ceramah terhadap Minat Donor Darah Pemula di Sekolah. 1(1), 16.

Trade, M. O. (n.d.). Corona Mewabah, Stok Darah di PMI Rekomendasi.

Wardati, Nur'aini, \& Hadi, A. . (2019). Open access Open access. Faktor Presdiposisi Ibu Usia Remaja Terhadap Pemberian ASI Eksklusif Pada Bayi Di Kecamatan Luahagundre Maniamolo Kabupaten Nias Selatan, 2(2), 165. https://doi.org/10.1119/1.2218359

Widarto, L. B. (2011). Kegiatan komunikasi dan partisipasi donor darah sukarela. 